Article

\title{
Location-Based Tracking Data and Customer Movement Pattern Analysis for Sustainable Fashion Business
}

\author{
Jonghyuk Kim ${ }^{1} \mathbb{D}$, Hyunwoo Hwangbo ${ }^{2} \mathbb{D}$, Sung Jun $\mathrm{Kim}^{3}$ and Soyean $\mathrm{Kim}^{4, *}$ \\ 1 Division of Computer Science and Engineering, Sunmoon University, Tangjeong-meyon, Asan-si, \\ Chungcheongnam-do 31460, Korea; jonghyuk@sunmoon.ac.kr \\ 2 Graduate School of Information, Yonsei University, Seoul 03722, Korea; greatemp@yonsei.ac.kr \\ 3 Department of Civil and Environmental Engineering, Seoul National University, Seoul 08826, Korea; \\ lalchemistl@snu.ac.kr \\ 4 Department of International Studies, Kyung Hee University, Yongin-si, Gyeonggi-do 17104, Korea \\ * Correspondence: sokim@khu.ac.kr; Tel.: +82-31-201-2324
}

Received: 19 September 2019; Accepted: 28 October 2019; Published: 6 November 2019

\begin{abstract}
Retailers need accurate movement pattern analysis of human-tracking data to maximize the space performance of their stores and to improve the sustainability of their business. However, researchers struggle to precisely measure customers' movement patterns and their relationships with sales. In this research, we adopt indoor positioning technology, including wireless sensor devices and fingerprinting techniques, to track customers' movement patterns in a fashion retail store over four months. Specifically, we conducted three field experiments in three different timeframes. In each experiment, we rearranged one element of the visual merchandising display (VMD) to track and compare customer movement patterns before and after the rearrangement. For the analysis, we connected customers' discrete location data to identify meaningful patterns in customers' movements. We also used customers' location and time information to match identified movement pattern data with sales data. After classifying individuals' movements by time and sequences, we found that stay time in a particular zone had a greater impact on sales than the total stay time in the store. These results challenge previous findings in the literature that suggest that the longer customers stayed in a store, the more they purchase. Further, the results confirmed that effective store rearrangement could change not only customer movement patterns but also overall sales of store zones. This research can be a foundation for various practical applications of tracking data technologies.
\end{abstract}

Keywords: sustainable fashion business; indoor positioning system; location-based tracking data; spatial analysis; geographic information system; visual merchandising display

\section{Introduction}

A visual merchandising display (VMD) develops a systematic floor plan that highlights the benefits of products, enabling customers to understand the characteristics of the store, brand, and products at a glance. VMDs are a commonly used strategy in the retail industry to maximize profits and deliver brand images to customers [1]. This strategy includes window displays, in-store product displays, product placement, and point-of-purchase displays. Effective VMDs can attract and engage customers. Furthermore, they can stimulate customers' desire to purchase products [2].

Interestingly, a change in VMD can transform not only store layouts but also customers' movement patterns. A VMD is expected to influence customer movement flows, distance, and length of time spent in the store [3]. By acquiring detailed information on in-store movement patterns of customers, retailers can create store layouts that increase shopper traffic, average transaction values, and profitability [4]. 
Thus, for retailers to maximize the space performance of their stores, accurate movement pattern analysis of customer tracking data has become an important task in the retail industry. In the extant literature, however, researchers struggle to precisely measure customers' movement patterns and their relationships with sales [5,6]. This research overcomes such hurdles by adopting information technology (IT), such as wireless sensor devices and fingerprinting techniques for tracking and comparing customers' movements before and after the VMD change. In addition, this research connects consumers' movement data with sales data to help practitioners find optimal space layouts.

In this research, we conduct three field experiments in a fashion retail store and track the movements of customers both inside and outside the store. Our objectives are (1) to identify meaningful changes in customers' movement patterns through big data analysis, (2) to suggest an effective VMD strategy, and (3) to examine changes in customers' movement patterns before and after three critical store VMD modifications. The method used involves collecting in-door positioning and movement pattern data through a wireless sensor network, and utilizing these data to suggest potential VMD strategies to maximize sales. We use fingerprinting as our main data collection technique, because it does not require line-of-sight measurement of access points (APs); moreover, it provides highly accurate calculations in complex indoor environments.

The rest of this paper is organized as follows. In Section 2, we review related works on visual merchandising and indoor positioning system (IPS) to gain insights for effective VMD strategies. In Section 3, we describe our research design, including the experimental settings, data collection process, and method. Section 4 presents the data analysis process and compares the experimental results before and after the VMD changes. In Section 5 , we discuss theoretical and practical implications of our findings.

\section{Background and Literature Review}

\subsection{Visual Merchandising and Customer Movement Patterns}

A visual merchandizing display (VMD) indicates collective planning and managing of product displays to appeal to customers and differentiate one brand from other brands. Specifically, a VMD determines how a product is presented and offered to consumers in the planning and purchasing stages. It presents the product to a customer in a way that effectively delivers the benefits of the product and prominently appeals to brand values. It is often considered an opportunity to increase sales by highlighting promotions and guiding customers into previously unnoticed areas in stores.

One element of VMD, product placement, has been manipulated in our three field experiments as the change in product arrangements is expected to transform customers' movement patterns. Product placement refers to the grouping of goods according to their characteristics, customer demand forecast, and consumer psychology and is known to directly influence sales and customer purchasing behavior. In addition, the placement of goods involves planning product displays by considering the purchasing behavior of customers and the characteristics of the goods or arranging products for easy buying and selling [7,8]. Proper placement of goods provides customers with easy-to-find merchandise and clarifies the image of the store. In addition, it affects customers' movement flows in a store, such as the length of stay in the store and moving distances [3]. In contrast, inefficient product placement can cause congestion in a store and make customers' product purchases more difficult. Thus, retailers should carefully consider sales proportion, sales frequency, price, and product size when arranging products. An efficient floor plan can maximize the use of store space and make products stand out.

In previous studies on product placement, Waechter et al. [9] found that corner arrangements with vertical openness are more visually advantageous than flat-type hallway arrangements. This suggests that the position of the product plays a major role in shopping when the product is placed in a better visual position along the movement path. De Gregorio and Sung [10] explain that the design of shopping paths should allow customers to stay for a long time, and that shopping lines should be able to help customers make purchase decisions efficiently through proper product arrangement. Williams 
et al. [11] found that the placement of new items increases the chances of customers purchasing items compared to the initial product placement. Wu et al. [12] conducted a study on product placement decisions of large discount stores and found that placement serves as a major determinant of customer movement in the store. Product placement affects the customer's length of stay in the store, which, as a determinant of impulse purchasing, in turn influences sales volume. In addition, reorganization of products and installation of themed corners among related products are proposed as measures to eliminate flow imbalance in a store. These studies indicate that product placement influences various factors, such as composition and circulation of stores, and is highly relevant to consumers' purchasing. In the field experiments, we change the position and orientation of customer seating, a window dummy (mannequin), and hanger, with a focus on comparing customers' movements before and after the relocation.

Much of the above research focuses on identifying important elements of VMD. Some scholars extend their research by examining the relationship between VMD elements and customer behaviors. However, most customer behavior data are self-reported survey data. The significance of our research lies in our use of wireless technology when collecting real-time data of customers' movements. Further, our research combines two different types of customers' behavior data-customers' movement tracking data and purchase data-to make our analysis meaningful not only to academic researchers but also to practitioners. Table 1 summarizes our contribution in the extant literature.

Kernel density analysis, one of the common methodologies of GIS (geographic information system), estimates the spatial density of a dimension represented by a point [13]. As more points are distributed around one point, the spatial density at that point increases. In estimating spatial density, the wider the bandwidth or search radius that represents the geographic range, the greater the influence between the points. This principle can be fully utilized in defining the sequential relationship of data or elements in this study. We can apply principles such as spatial-chromatic histogram (SCH), a cost-effective representative methodology of spatial analysis, and utilize the function of CPTED (crime prevention through environmental design). SCH is the new indexing methodology for image databases integrating color and spatial information for content-based image retrieval. This methodology, synthesizing in few values information about the location of pixels having the same color and their arrangement within the image, can be more suitable than other typical and standard techniques [14]. In addition, CPTED using SCH establishes active defense space planning in architectural and urban design. Creating such a physical environment can protect citizens from potential crimes and reduce criminal opportunities for criminals by improving their quality of life [15]. This principle considers both color and light based on the condition that the impression of the reflected object or space is clearly different according to the type of light source.

Table 1. Summary of research on VMD.

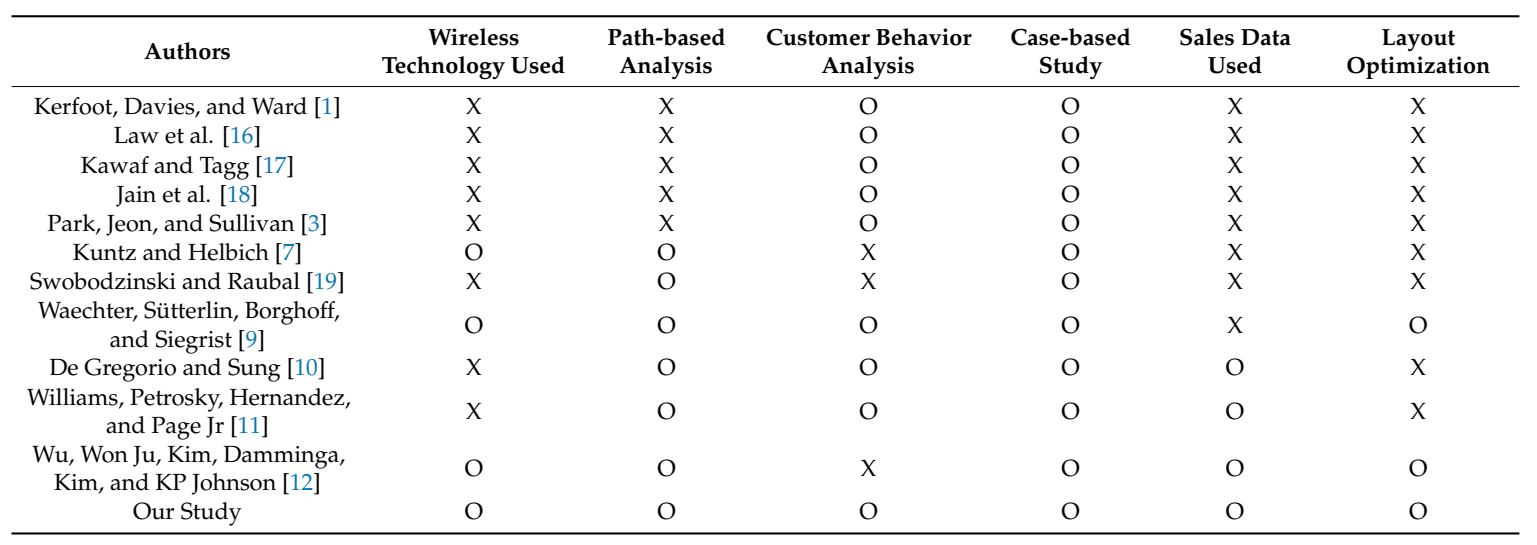




\subsection{Mobile Tracking Data—Indoor Positioning System}

A new type of mobile technology, known as indoor positioning technology systems (IPS), enables the collection of massive human-tracking data in indoor settings. Recently, researchers have begun recognizing the value of indoor location data analysis [20-24]. An IPS is a technology employed to locate objects or people in a building through radio waves, magnetic fields, acoustic signals or other sensory information using mobile devices [25]. The indoor location market is expected to grow from $\$ 935$ million in 2014 to $\$ 4424$ million by 2019, an estimated compound annual growth rate of 36.5\% from 2014 to 2019 . In particular, beacon technology is expected to increase the use of active beacons from about 30,000 at the beginning of 2015 to nearly 4.5 million by the end of 2018 [6]. Localization techniques based on radio frequency $(\mathrm{RF})$ are implemented through a mobile application or Wi-Fi-enabled device that interacts with sensors and is largely composed of triangulation, proximity, radio fingerprinting, and dead-reckoning technology [26]. In the following subsections, we explain RF-based indoor measuring principles that have become commercially available and research oriented.

\subsubsection{Triangulation}

Triangulation, which is a model-based approach, uses the geometric properties of triangles in order to estimate target location [27]. Triangulation is categorized into trilateration, which measures the distance from anchors, and triangulation, which measures the angle to anchors. The trilateration technique measures the distance between objects and multiple reference points to estimate the location of objects, and often uses methods that compute the attenuation of the emitted signal strength or multiply the radio signal velocity and travel time. The main techniques of trilateration include the received signal strengths, time of arrival, time difference of arrival, roundtrip time of flight, and received signal phase models. The triangulation technique computes angles related to multiple APs to estimate the location of objects, and often uses angle of arrival estimation. Mathematical modeling based on inverse trigonometry and probabilistic models, such as Bayesian statistical analysis and Kalman filtering, are used as methods for approximating signal propagation [28]. When triangulation is used, there are often errors in indoor environments, because radio signals cannot be linearly transmitted owing to walls and other obstructions. To resolve this, ultra-wide bands or ultrasound identification are used.

\subsubsection{Radio Fingerprinting}

Radio fingerprinting conducts site surveys for fingerprint map construction, assuming that each location has a specific signal characteristic. In addition, a signal from each device is connected to a fingerprint map through various algorithms [29]. Fingerprinting takes two steps to collect signals: the offline training phase (survey) and the online position determination phase (query) [30]. In the offline phase, the vectors of received signal strength indicators (RSSI) of Wi-Fi signals collected from multiple APs located at all reference points are checked [31]. The algorithm of fingerprinting mainly uses deterministic methods and statistical methods. The deterministic methods include Euclidean distance, cosine similarity, k-nearest neighbor, support vector machine, and linear discriminant analysis. Statistical methods include Bayesian network, expectation maximization, Gaussian process, and smallest M-vertex polygon [32]. Fingerprinting does not require many APs and has the advantage of producing high accuracy in complex indoor environments [33].

This research utilizes indoor positioning and fingerprinting as our main data collection technique. This technique allows us to collect customers' location data through a wireless sensor network to identify customer movement patterns. Furthermore, it provides highly accurate calculation of customers' locations. 


\section{Research Design}

\subsection{Experimental Settings}

\subsubsection{Objective}

In this research, we conducted three field experiments at different times. All three experiments were conducted in one retail store of a Korean apparel company. For these experiments, we traced the mobile identities of visiting customers to track their movement patterns and purchases. Our objectives were to (1) connect customers' discrete location data to identify meaningful patterns in customers' movements through big data analysis, (2) develop methods to match the identified movement pattern data with sales data using customers' location and time information, and (3) examine the changes in customers' movement patterns before and after three critical store VMD modifications.

\subsubsection{Store Setting}

The store had two floors and was divided into six zones-three zones on the first floor (1F-right, 1F-left, and 1F-inner) and three zones on the second floor (2F-right, 2F-left, and 2F-inner). We assigned the MAC addresses of customers to one of six sections and examined the in-store movement patterns of customers. 1F-right, 1F-left, and 1F-inner included women's classical casual clothing, bags, and accessories, while 2F-right, 2F-left, and 2F-inner primarily contained men's clothing (see Figure 1).
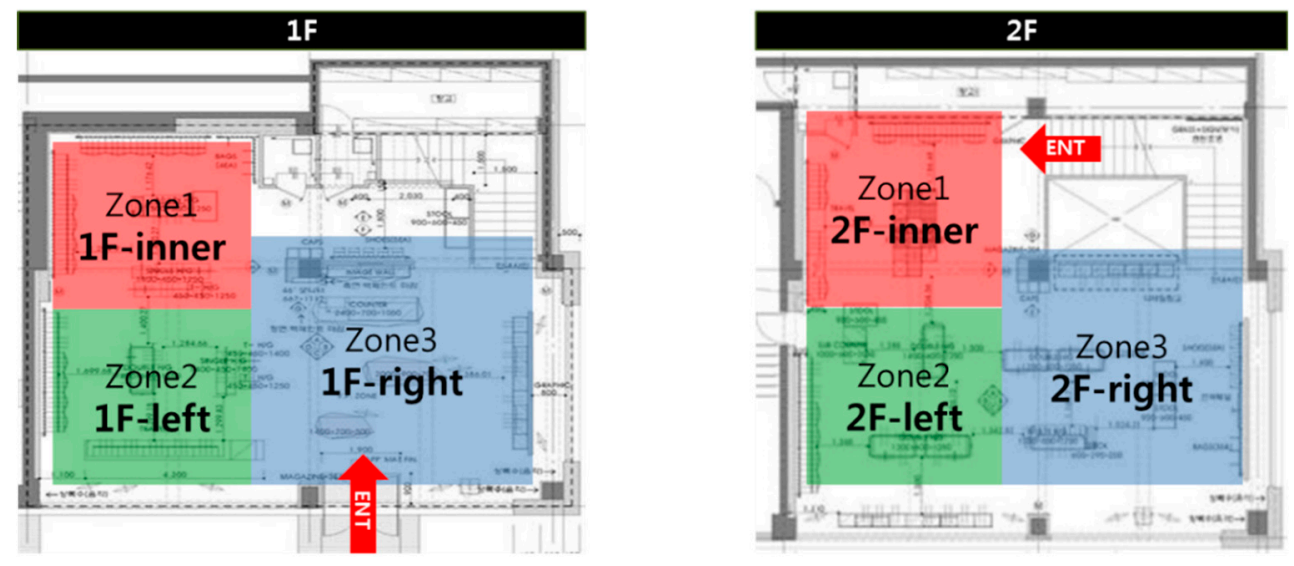

Figure 1. Store setting.

\subsection{Location-Based Tracking Technology}

Wireless signals (Wi-Fi) generated by smartphones are detected by sensors in the store. In a recent study related to mobile devices, the Wi-Fi activation index ratio is approximately $48.2 \%$ [34,35]. Therefore, assuming most visiting customers have mobile phones, about half of all mobile devices and their MAC addresses could be detected. We defined a dweller as a customer who moved to at least two or more places (or sections) to distinguish a dweller from a simple visitor. At this time, we connected mobile identifications that stayed in the 1F-right zone where the point of sale (POS) system was located with customers who generated sales data within $180 \mathrm{~s}$ from mobile detection to match the movement data detected by mobile phone with the company's sales data. In other words, a customer with a mobile identification was defined as a customer who had engaged in purchases using the POS system at that time. The fact that the number of customers with daily average actual sales is twice the number of mobile-detected buyers means that the Wi-Fi activation ratio is maintained throughout the purchase funnel.

Location-based tracking technology is capable of understanding customers' shopping behaviors without requesting extra actions, such as downloading an app and accessing the internet. It enables real-time data collection from $50 \%$ of all customers. It is more reliable than typical research sampling data from about $15 \%$ of all customers. Furthermore, it can identify the floating population around the 
store and the length of a customer's stay. This technology helps marketers create customer purchase funnels. With this technique, we were able to identify the causes of sales increases and decreases.

\subsection{Methodology}

\subsubsection{Data Transformation}

To understand how customers proceed from one location to another, we converted the location-based data from a store signal sensor device into movement pattern data. We set the signal detection term unit to $3 \mathrm{~s}$. The section with the lowest absolute value of RSSI among the frequencies detected redundantly in each section was defined as where the customer was located. The RSSI for a customer's mobile signal (Device_ID) at a specific time (TS) in a specific actual section (Square_Mac) is the raw data received from the device. We translated the raw data set into processed data. Specifically, the Time_Sequence was formed by the path passing through the specific section based on the Device_ID. The dwell time was computed when the customer stayed 5 times continuously $(3 \mathrm{~s} \times 5$ times) to reflect that the customer did not simply pass through a section but stayed for a sufficiently long time to browse.

\subsubsection{Process Mining}

A process miner was used to track the trajectory of movement sequences that resulted in the most sales to determine the tendencies the movement patterns produced. To analyze a customer's movement patterns, we made some basic assumptions. First, in the processed data, a minimum of two sections of the six in the m-area retail store was bundled into one ordered pair. This is because the objective of this study is to understand the movement patterns between sections and their relationships with sales. The second assumption is that there is a detected record with a minimum time (15 s) in the zone (1F-right), and then the actual sales data are present within $180 \mathrm{~s}$ of the detection. If this assumption was satisfied, we were able to classify the group of sales-generating customers. Finally, the movement pattern per person was converted into a node-specific data set. In other words, there are 30 routes in total for two (bi-) directional pairs for the six sections, and these 30 ordered pairs are the subject of analysis.

\section{Experimental Results}

\subsection{Overview}

In each field experiment, we rearranged one element of the VMD to compare customer movement patterns before (Round 1) and after (Round 2) the VMD change. In Study 1, we relocated display mannequins from the right-side zone near the entrance on the first floor (1F-right) to the inner side zone (1F-inner) and placed hangers with more clothing lines where the mannequin had been. In other words, customers were exposed to more of the store's merchandise when they entered the store through the entrance near 1F-right. Round 1 lasted for 2 months starting in September 2015, and Round 2 took another 2 months starting in November 2015. In Study 2, we relocated the mannequin on the second floor from the inner side zone (2F-inner) to the right-side zone (2F-right) to secure a wide range of moving lines toward 2F-right, where men's suits with large unit sales were displayed. Round 1 lasted for 2 months starting in December 2015 and Round 2 took another 2 months starting in February 2016. In Study 3, we cross-displayed men's and women's clothing lines. The effects of these rearrangements were measured by observing changes in sales.

\subsection{Study 1-Changing VMD on the First Floor}

\subsubsection{VMD Rearrangement Decision}

The 1F-right zone on the first floor focused on promoting new products by building mannequins, rather than hanger-based layouts that display many products. However, even though this zone was 
the entrance to the store and had the highest market share, its sales proportion was low. On the other hand, the market share and sales of the 1F-left zone were not large compared to the display products owing to weak connection lines, and even though popular women's sportswear and travel clothes were on display. To solve this problem, we changed the location of the mannequins in the 1F-right zone and the hanger in the $1 \mathrm{~F}$-left zone. In this way, we designed a line to increase sales by displaying many products in the $1 \mathrm{~F}$-right zone, which had high market share, and reinforced the entry into the left area after customers entered the store.

\subsubsection{Purchase Funnel}

As shown in Figure 2, the purchase funnel was constructed by detecting the mobile identifications of customers for the 4 months of the study, and by identifying customers who made final purchases. On average, 183 customers visited the store per day in Round 2. This accounts for $1.4 \%$ of the total floating population outside the store (13,667 per day). Furthermore, the purchase rate increased from $9.1 \%$ to $12.2 \%$, which indicated that among the total dwellers who visited and stayed in the store to look around, $12.2 \%$ made actual purchases.

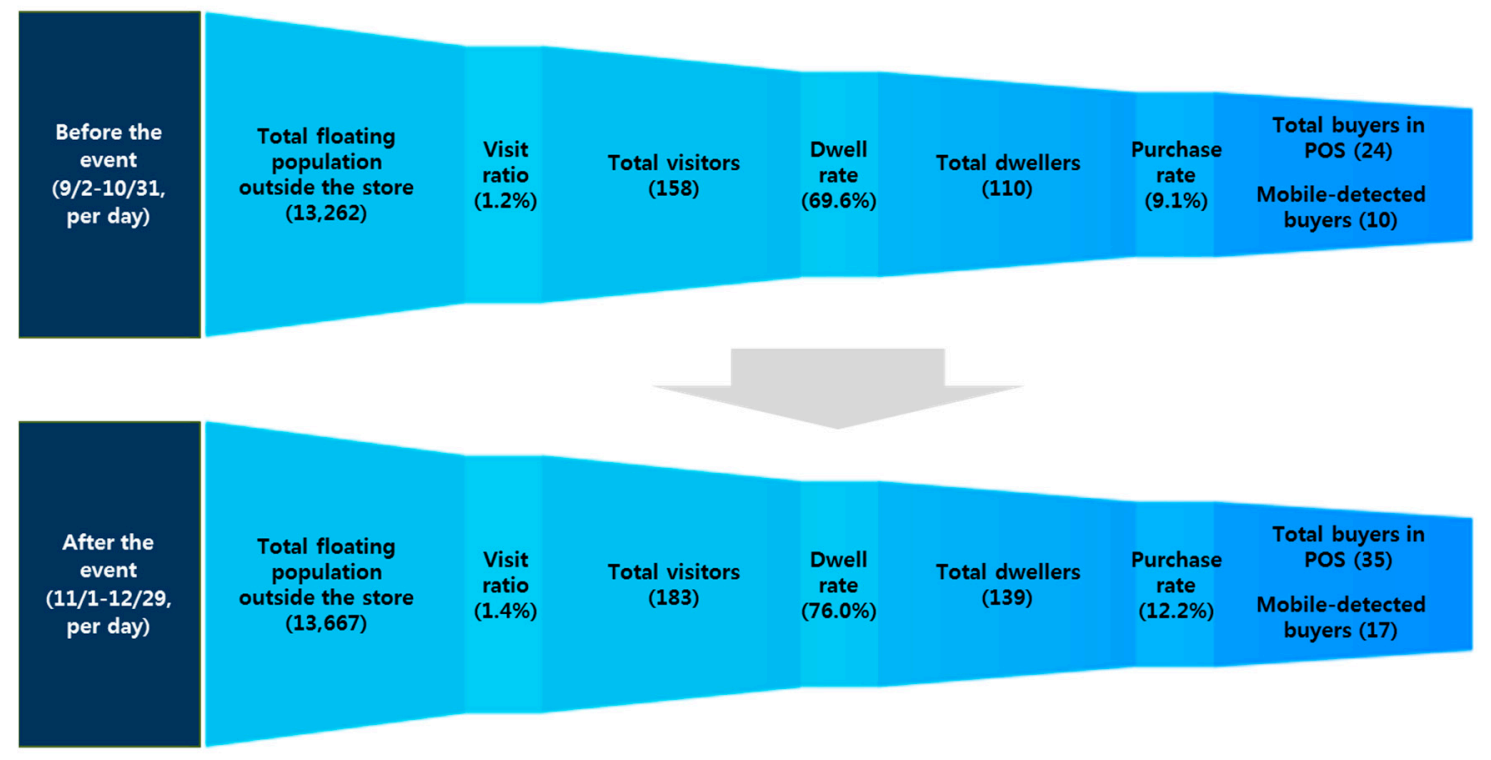

Figure 2. Purchase funnel.

\subsubsection{Bounce Rate}

Before the VMD rearrangement (Round 1), about 30\% of customers left the store after looking around the 1F-right zone. Among the $70 \%$ of customers who stayed, $43 \%$ exited the store after observing one section of the first floor. After rearrangement, about $24 \%$ of customers left the store right away (see Figure 2). The rearrangement decreased the bounce rate from $30 \%$ to $24 \%$. The remaining $76 \%$ of customers proceeded to other areas of the store.

\subsubsection{Share of Movements}

Before the rearrangement, the share of customer movements in the 1F-right zone was high, but sales from that area were low (see Figure 3). As shown in Figure 3, the share of movements in the 1F-left zone sharply decreased after the mannequins and hanger positions were rearranged and more women's clothing lines were located in the 1F-right zone. On the other hand, the share of movements in the 1F-right zone increased from $46 \%$ to $51 \%$. Even after the rearrangement, customers' moving paths (represented by the thickness of the red arrow) appeared similar, but the increase in the share of movements led to the increase in sales (see Figure 4). 

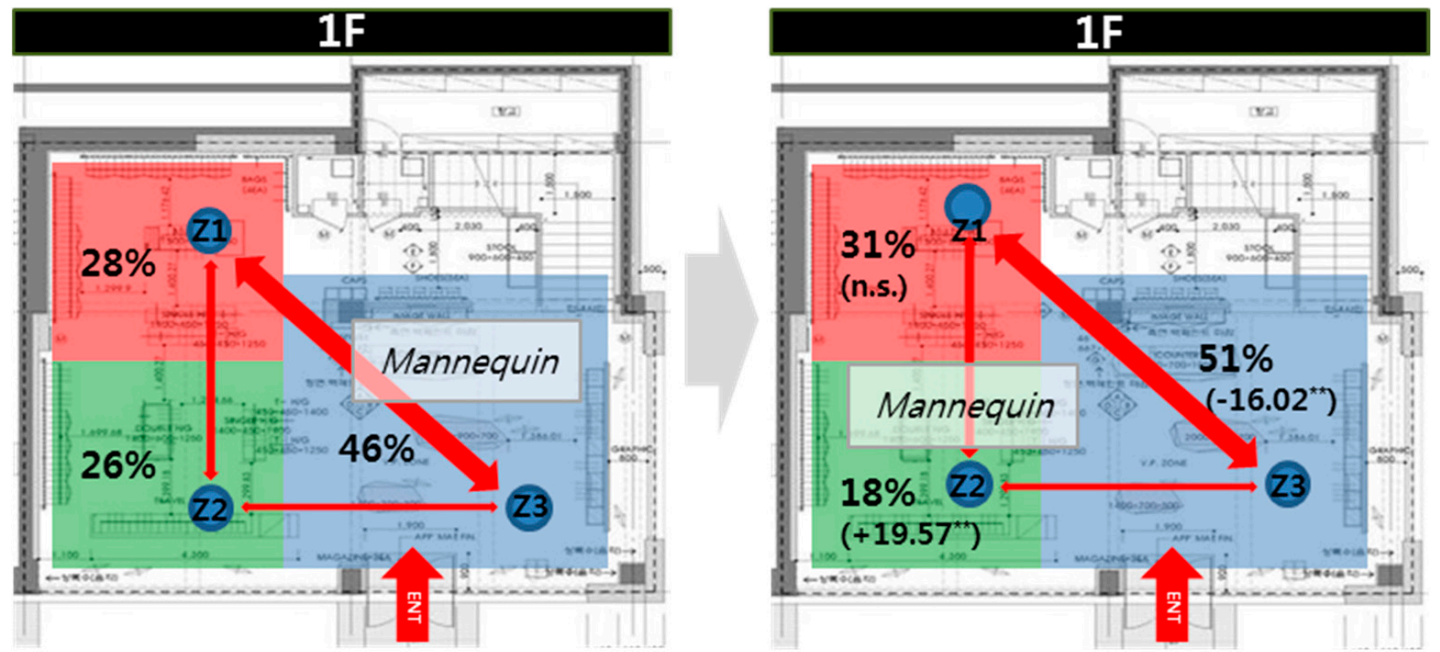

Figure 3. Share of movements (1st floor).

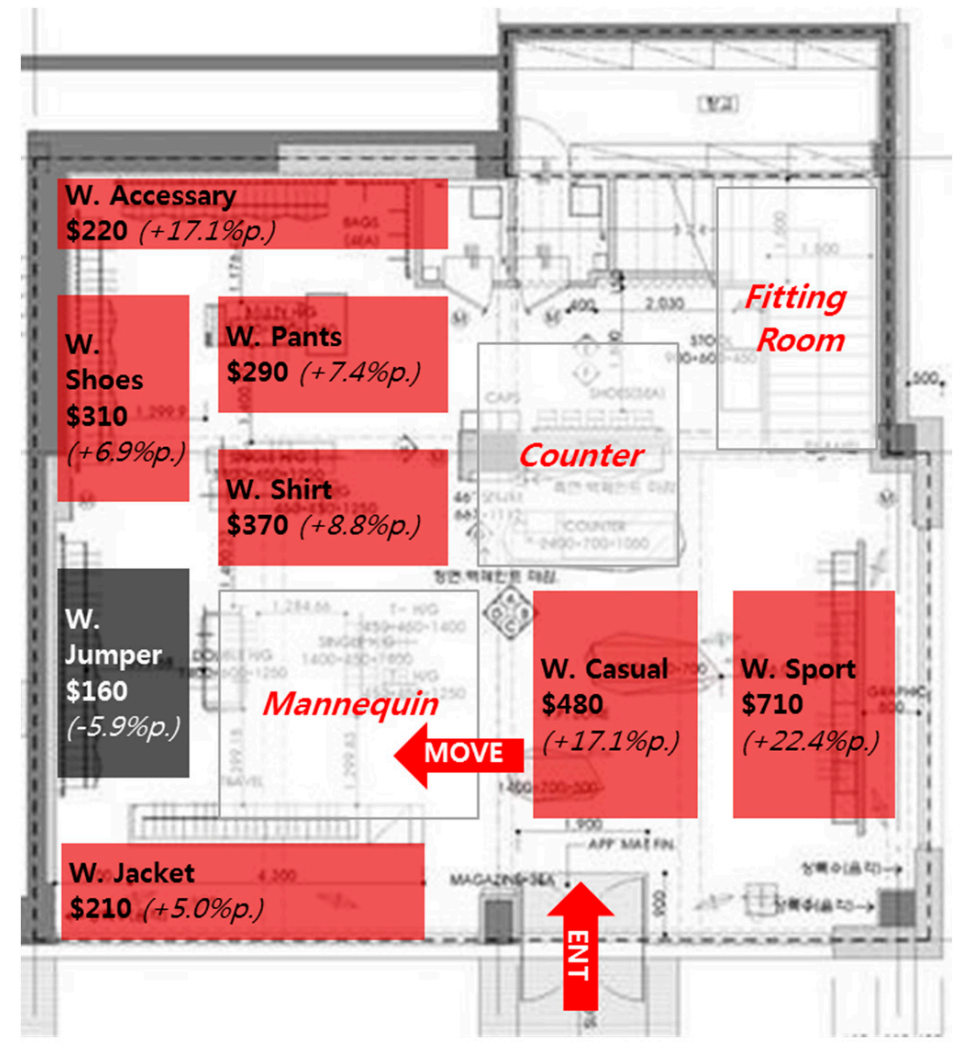

Figure 4. Sales change map (1st floor).

For statistical verification, we compared the customer shares for each of the previous and post 60 days in Table 2 and the results of the t-tests for each first-floor section are -1.86 (n.s.), $19.57^{* *}$, and $-16.02^{* *}$, respectively ( $n=60$ per group). The $t$-test is the statistical hypothesis test in which the test statistic follows a Student's t-distribution under the null hypothesis. A t-test is most commonly applied when the test statistic follows a normal distribution if the value of a scaling term in the test statistic is known. The t-test can be used, for example, to determine whether the means of two sets of data are significantly different from each other. This result confirmed that the changes in customer movement share in the 1F-right and 1F-left zones were statistically significant. 
Table 2. t-test for comparing customer movement patterns in two periods (1st floor).

\begin{tabular}{cccccccc}
\hline Zone & Group & $\mathbf{N}$ & Mean & Standard Deviation & Standard Error & $t$-Value & $p$-Value \\
\hline \multirow{2}{*}{ 1F-inner } & Round 1 & 60 & 0.2806 & 0.0996 & 0.0129 & -1.86 & n.s. \\
& Round 2 & 60 & 0.3149 & 0.1023 & 0.0132 & & \\
\multirow{2}{*}{ 1F-left } & Round 1 & 60 & 0.2531 & 0.0199 & 0.0028 & 19.57 & \\
& Round 2 & 60 & 0.1810 & 0.0205 & 0.0026 & & \multirow{2}{*}{ 1F-right } \\
& Round 1 & 60 & 0.4586 & 0.0149 & 0.0019 & -16.02 & \\
\hline
\end{tabular}

${ }^{*} p<0.05,{ }^{* *} p<0.01$, Satterthwaite was applied to Z3 due to unequal variances.

\subsubsection{Stay Rate}

The rearrangement increased customers' stay rate on the first floor from $30 \%$ to $43 \%$.

\subsubsection{Sales}

After the VMD rearrangement, the average daily sales of the first floor increased by about $10.6 \%$ from $\$ 5490$ to $\$ 6070$. Interestingly, the VMD change in the first floor also increased the number of customers browsing the second floor, since the overall bounce rate went down. Thus, the average daily sales of the second floor rose by about 9.9\% from $\$ 3020$ to $\$ 3320$. Figures 4 and 5 show the changes in sales for each category after the rearrangement.

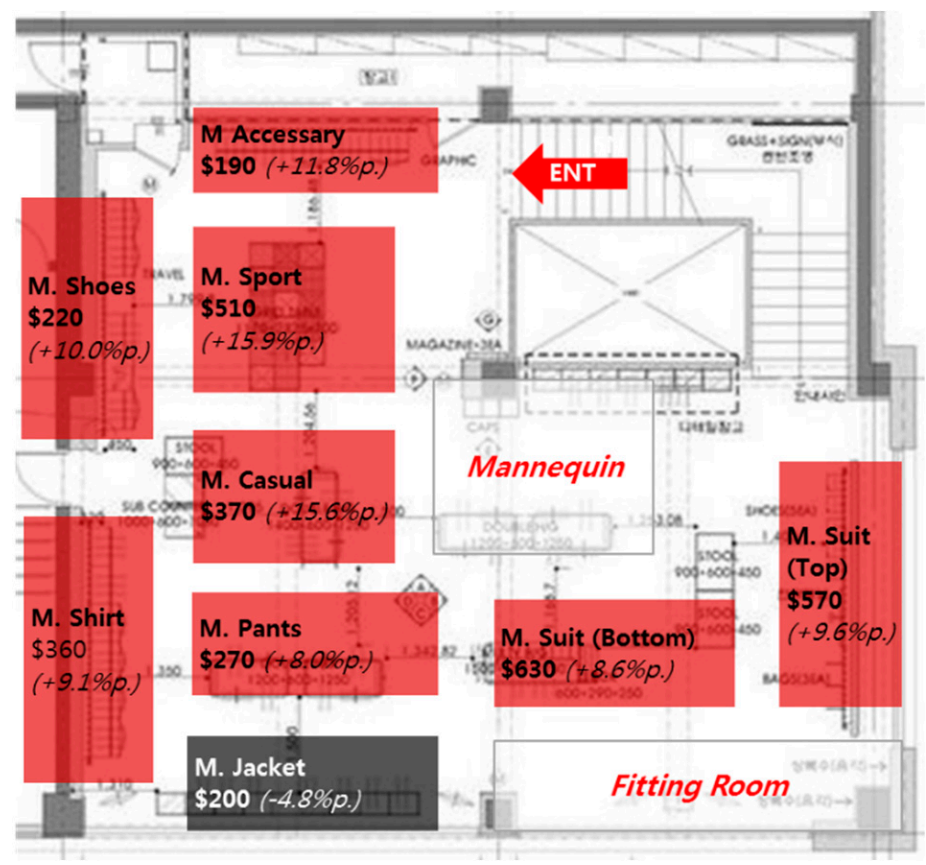

Figure 5. Sales change map (2nd floor).

The basic preconditions for implementing the movement pattern algorithm using process mining are as follows. First, we presented only two movement sequences from the initial node when consumers proceeded to the next node. In other words, from one particular zone (a node in Figure 6) in the store, on a link-by-number basis, we only showed customers' movements to the first and second rank zones (nodes). To simplify the figure and help readers interpret the process mining results, we did not consider movements to the third rank. Second, as mentioned earlier, we set the signal detection term to $3 \mathrm{~s}$. For Figure 6, if the customer remained in a specific zone for 60 detection terms, that is, $3 \mathrm{~min}$, we defined this as "stay" for one node, the unit we created for the drawing. 

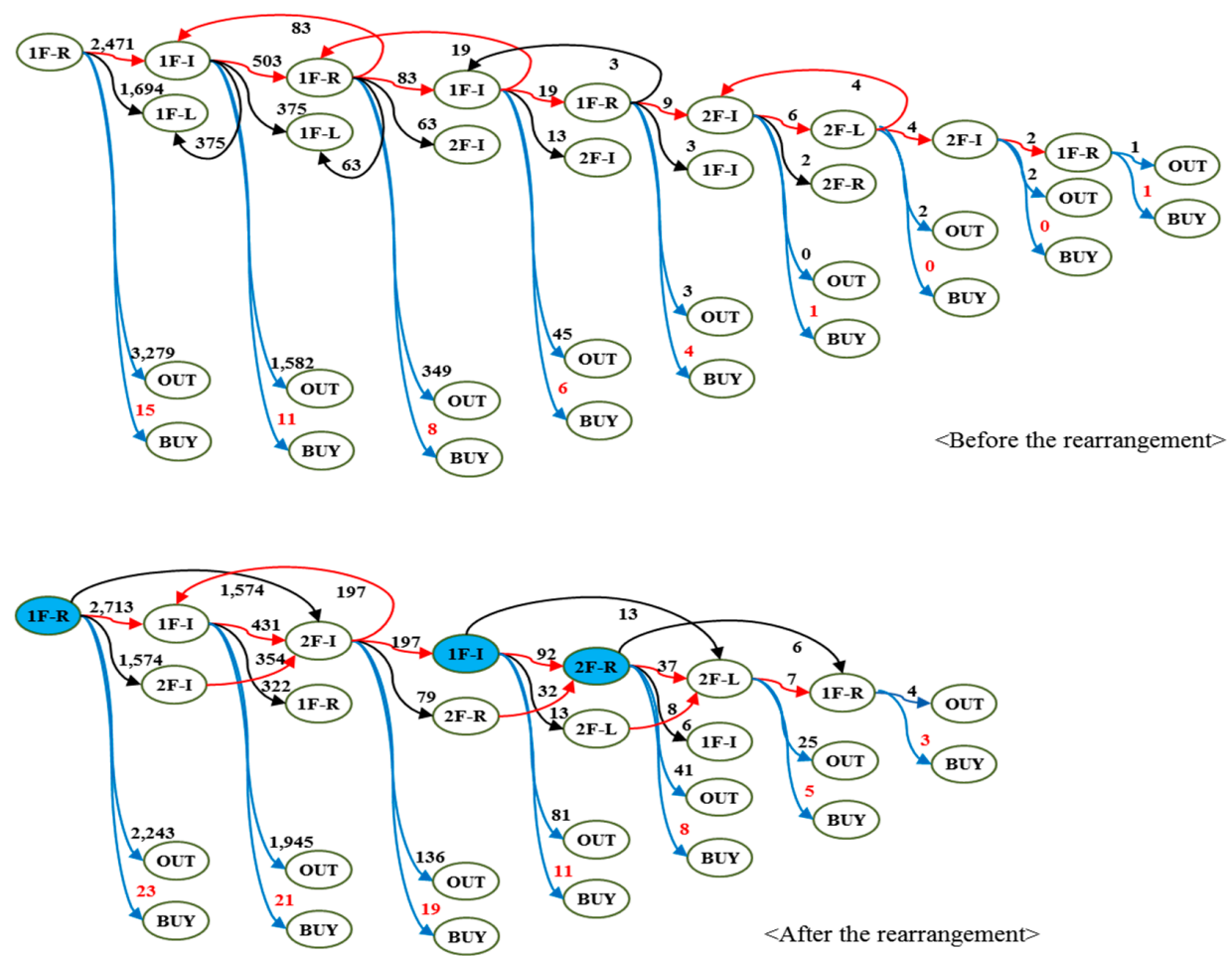

Figure 6. Comparison of movement patterns (process mining).

After the VMD rearrangement, we observed that a second ordered node in the previous step often became a first rank node for the next step. For example, customers entered $1 \mathrm{~F}-\mathrm{R}$ and the majority proceeded towards either 1F-I or 2F-I. Interestingly, the second ordered node, 2F-I became the first ordered node for the next stage. This result indicated that some specific zones in the store attracted more movements. Thus, the length of stay in a particular zone and the average transaction value increased, while the total length of stay in the store was shortened. This result was contrary to the findings in existing literature that suggested the longer customers stay in a store, the more they purchase. Our study, which classified customers' movement patterns in more detail by time and order, found that stay time in a particular zone had a greater impact on sales than total stay time of a customer.

Finally, from the results of the process mining shown in Figure 6, before the rearrangement, customer circulation between the first floor and the second floor did not flow freely. In other words, customers moved around on the first floor in the early stage and proceeded to the second floor in the latter part of their shopping. However, after rearrangement, different movement patterns were observed; customers started to travel freely between the first and second floors. This phenomenon might be evidence for the creation of a virtual cycle in customers' movement patterns.

\subsection{Study 2-Changing VMD on the Second Floor}

\subsubsection{VMD Rearrangement Decision}

In the case of the second floor, the section that the customer first encountered was 2F-inner. The problem of the second floor was that accessibility to the 2F-right zone was low, owing to the mannequin display en route from $2 \mathrm{~F}$-inner to $2 \mathrm{~F}$-right. Once the customer had climbed the stairs from the first floor, the mannequins were located at the entrance, so that the moving paths to the 2F-right section were actually blocked, and most customers went to 2F-right through 2F-left (see Figure 7). This might have hurt sales, since 2F-right was expected to have a positive effect on overall sales if the accessibility and length of time in the store increased, because expensive men's suits were displayed in this section. Thus, we relocated the mannequin to the $2 \mathrm{~F}-$ left zone and secured a sufficient moving path toward the 2F-right zone. 

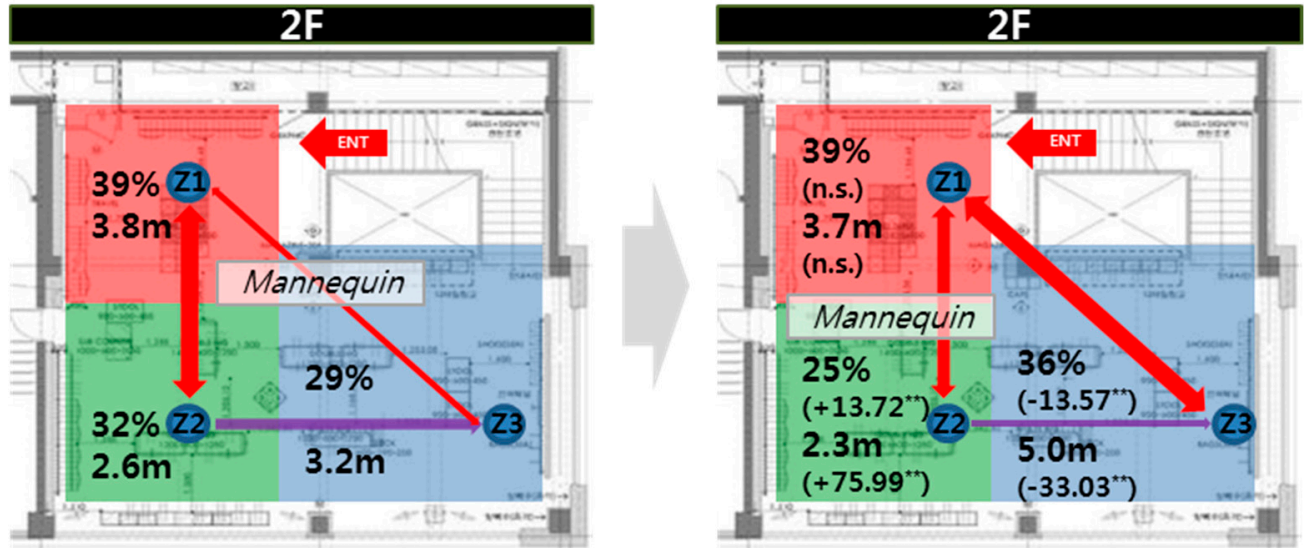

Figure 7. Share of movements (2nd floor).

\subsubsection{Share of Movements}

After the VMD rearrangement on the second floor, the share of movements in the 2F-right zone increased from $29 \%$ to $36 \%$. The case of the $2 \mathrm{~F}$-right zone and the reason the number of customers shown as "OUT" is lower as shown in Figure 6 can be seen as two different key factors for sales optimization pursued in this study. In other words, the first issue is that the 2F-right zone men's suits have the highest unit price, so the basic and direct purpose of the VMD rearrangement was to guide the customer to this zone. In addition, we could conclude that this is an example of sales improvement. The second issue was to create a circulation structure that reflected customer needs, and shortened the steps of the overall process, thereby increasing the number of customers moving to other areas rather than leaving immediately. In addition, it was confirmed that customers who moved to the other areas ultimately increased their dwell time, and thus their chances of purchasing increased, consequently contributing positively to the increase in sales.

\subsubsection{Length of Stay}

Customers' average length of stay in the 2F-right zone increased from $3.2 \mathrm{~min}$ to $5.0 \mathrm{~min}$. The average length of stay of customers on the second floor increased from $9.6 \mathrm{~min}$ to $11 \mathrm{~min}$ or $14.6 \%$.

In this case, we conducted a t-test on the difference in dwell time (time) and movements share (share) between the previous 60 days (Round 1) and the post change 60 days (Round 2). The results confirm that the increase in dwell time of customers in the 2F-right zone is statistically significant (Table 3).

Table 3. $t$-test for comparing two periods in duration time (2nd floor).

\begin{tabular}{|c|c|c|c|c|c|c|c|c|}
\hline Zone & Division & Group & $\mathbf{N}$ & Mean & Standard Deviation & Standard Error & $t$-Value & $p$-Value \\
\hline \multirow{4}{*}{ 2F-inner } & \multirow[b]{2}{*}{ share } & Round 1 & 60 & 0.3881 & 0.0199 & 0.0026 & \multirow[b]{2}{*}{-0.78} & \multirow[b]{2}{*}{ n.s. } \\
\hline & & Round 2 & 60 & 0.3910 & 0.0205 & 0.0026 & & \\
\hline & \multirow[b]{2}{*}{ time } & Round 1 & 60 & 3.7773 & 0.2685 & 0.0347 & \multirow[b]{2}{*}{1.37} & \multirow[b]{2}{*}{ n.s. } \\
\hline & & Round 2 & 60 & 3.7176 & 0.2030 & 0.0262 & & \\
\hline \multirow{4}{*}{ 2F-left } & \multirow{2}{*}{ share } & Round 1 & 60 & 0.3178 & 0.0279 & 0.0036 & \multirow[b]{2}{*}{13.72} & \multirow[b]{2}{*}{ ** } \\
\hline & & Round 2 & 60 & 0.2465 & 0.0290 & 0.0038 & & \\
\hline & \multirow[b]{2}{*}{ time } & Round 1 & 60 & 2.5981 & 0.0224 & 0.0029 & \multirow{2}{*}{75.99} & \multirow{2}{*}{$* *$} \\
\hline & & Round 2 & 60 & 2.3018 & 0.0203 & 0.0026 & & \\
\hline \multirow{4}{*}{ 2F-right } & \multirow{2}{*}{ share } & Round 1 & 60 & 0.2885 & 0.0341 & 0.0044 & \multirow{2}{*}{-13.51} & \multirow{2}{*}{$* *$} \\
\hline & & Round 2 & 60 & 0.3561 & 0.0184 & 0.0024 & & \\
\hline & \multirow[b]{2}{*}{ time } & Round 1 & 60 & 3.2090 & 0.2974 & 0.0384 & \multirow{2}{*}{-33.03} & \multirow{2}{*}{$* *$} \\
\hline & & Round 2 & 60 & 5.0381 & 0.3091 & 0.0399 & & \\
\hline
\end{tabular}

${ }^{*} p<0.05,{ }^{* *} p<0.01$, Satterthwaite was applied to Z1 (D.T.) and Z3 (C.S.) due to unequal variances. 


\subsection{Study 3-Cross Displaying}

\subsubsection{Cross-Displaying Decision}

By cross-displaying products, we removed the stereotype that the first floor was for women's clothing, and the second floor was for men's clothing. This strategy is known to stimulate mixed purchases of men's and women's products. In particular, according to previous studies, about $96 \%$ of male customers search for male products in stores, while $67 \%$ of female customers search for male products in stores [16]. With this rearrangement, we attempted to show the effects of cross-displaying on customers' movement patterns and sales.

\subsubsection{Sales}

After cross-displaying (mixing) men's wear and women's wear, the average number of purchasers per day increased from 24 to 35. The number of products sold increased from an average of 44 to 53 per day. In particular, the average daily sales of women's products on the first floor increased by $10 \%$, thereby increasing total average daily sales to $\$ 10,247$.

The sales of goods in the 2F-inner and 2F-right zones decreased compared to the average sales of other stores. On the first floor, such clothing lines as men's jumpers showed a decline in sales but this difference was minimal compared to the average sales of other stores (Figure 8). On the second floor, two clothing lines, namely, women's sport wear and men's sport wear, showed a decrease in sales, but the average sales were higher than those of other stores (Figure 9). The overall sales on the second floor increased. Moving the mannequin to the 2F-left zone opened the path to the 2F-right zone, and the average sales of products in the 2F-right zone increased in Round 2 compared with those of other stores. In the 2F-left zone, however, there was a slight decrease in sales in Round 2.

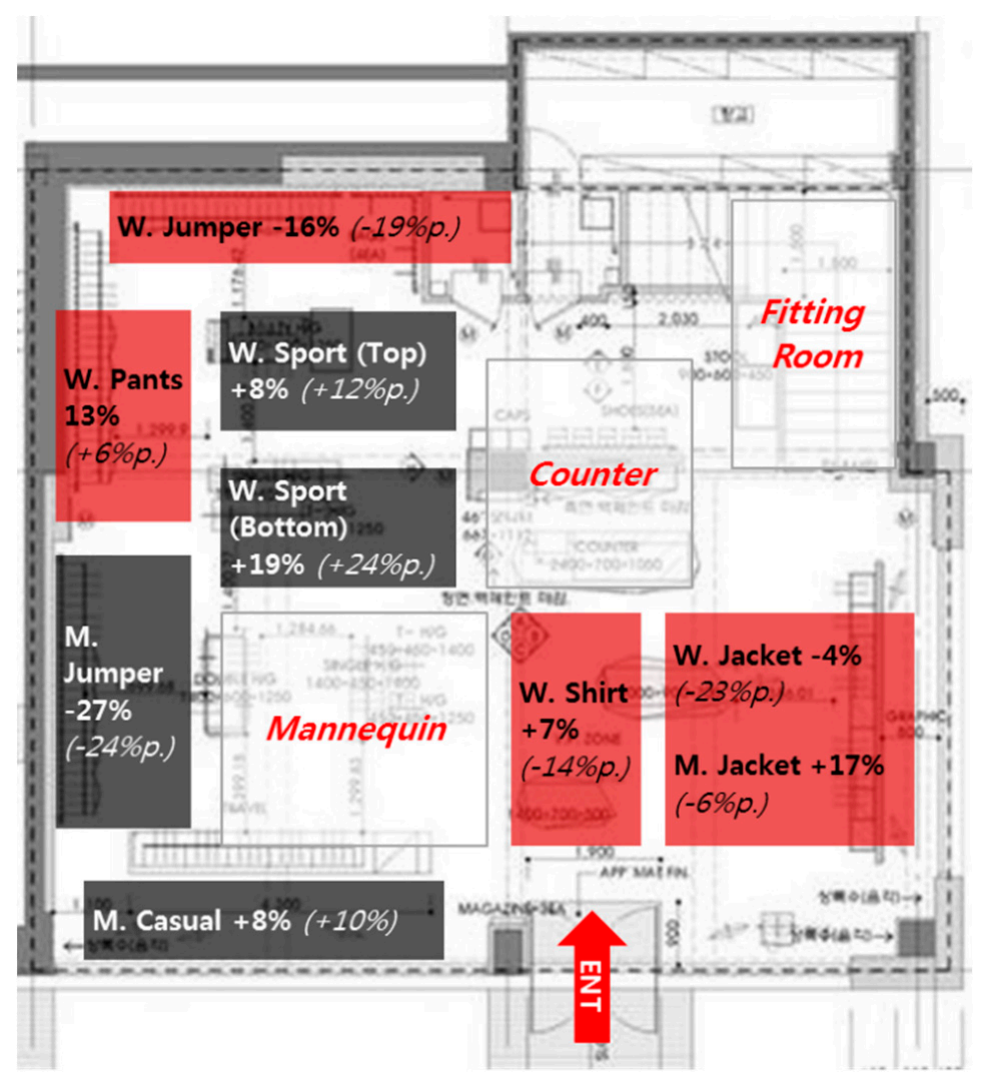

Figure 8. Sales change map on cross-displaying (1st floor). 


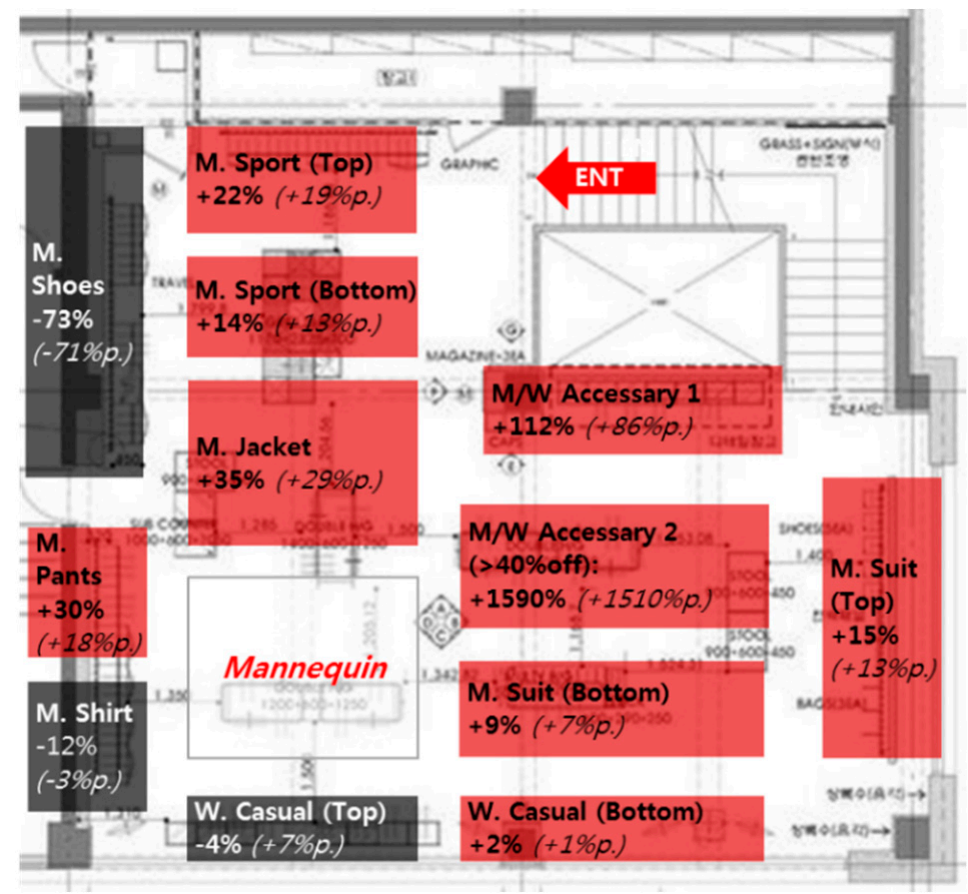

Figure 9. Sales change map on cross-displaying (2nd floor).

\subsubsection{Sales Breakdowns}

In addition, we conducted a sales breakdown for each route using process mining to determine which movement pattern contributed most in terms of sales. The process-mining unit is the customer's path between two sections, not the customer himself or herself. In other words, 30 ordered pairs of six sections were identified, and the sales amount per person was calculated by dividing the revenue generated from each node by the total number of units in that step. The movement patterns before and after the rearrangement were compared by searching for the two strongest lines of nodes (the highest amount of sales) based on the highest sales in the final node.

Overall, the sales in Round 2 after cross-displaying increased by about $10.6 \%$ (Table 4). Specifically, in the 2F-right section, which sold men's suits, it can be observed that the proportion of sales is considerably larger in both periods. As a result of cross-displaying, the proportion of sales compared to the total on the second floor increased substantially in Round 2. By contrast, sales along routes to the $1 \mathrm{~F}-\mathrm{left}$ and 2F-left zones decreased owing to the changed movement patterns. In addition, the route to the 2F-right zone, a newly opened route, showed increased sales in Round 2.

As shown in Figure 4, we found that the changes in the sales after store rearrangement was statistically significant. However, we did not control for the seasonality. However, we compared the seasonal sales data in our experiments with the data from 2016 to 2017 (September-October vs. November-December). We observed an increase of $4.7 \%$ in sales between two specific periods in 2016 and 5.3\% in 2017. In other words, average seasonal changes in sales were around 5\%. However, the 2018 data showed $10.6 \%$ increase in sales that is considerably larger than general seasonal variations. We compared the difference in sales over the three years of 61 days to observe the significant increase in sales for the year-end season through the difference between three years of September-October and November-December sales.

We used SAS Enterprise Guide 8.1, and Table 5 shows the ANOVA table for the difference in sales for each year and LSM (least square means) by multiple comparison. This value is a test result comparing three years' before and after sales, and the result shows that there is a difference in sales by year when the null hypothesis is rejected when the $p$-value is less than 0.05 . In addition, we proved that there was no statistical difference between before and after 2016 and 2017 ( $p$-value is 0.1021) based on 
the result of Tukey-Kramer's adjustment for multiple comparisons, and on the contrary, 2018 showed a clear difference from the previous years ( $p$-value is $<.0001)$. Based on this comparison, we argue that this increase in sales is the result of store rearrangement.

Table 4. Sales breakdowns by route after the rearrangement.

\begin{tabular}{|c|c|c|c|c|c|c|}
\hline \multirow{2}{*}{$\begin{array}{l}\text { Bi-Directional } \\
\text { Route (30) }\end{array}$} & \multicolumn{2}{|c|}{ Previous Period (Sep. to Oct.) } & \multicolumn{2}{|c|}{ Post Period (Nov. to Dec.) } & \multirow{2}{*}{ Changes (\%) } & \multirow{2}{*}{$t$-Value (Sig.) } \\
\hline & Sales (\$) & $\%$ & Sales (\$) & $\%$ & & \\
\hline $1 \mathrm{~F}-\mathrm{R} \rightarrow 1 \mathrm{~F}-\mathrm{L}$ & 23,474 & 4.1 & 23,071 & 3.7 & -1.72 & $21.14^{* *}$ \\
\hline $1 \mathrm{~F}-\mathrm{R} \rightarrow 1 \mathrm{~F}-\mathrm{I}$ & 23,582 & 4.1 & 28,812 & 4.6 & 22.18 & $17.89^{* *}$ \\
\hline $1 \mathrm{~F}-\mathrm{R} \rightarrow 2 \mathrm{~F}-\mathrm{I}$ & 24,624 & 4.3 & 30,048 & 4.8 & 22.03 & $-47.57 * *$ \\
\hline $1 \mathrm{~F}-\mathrm{R} \rightarrow 2 \mathrm{~F}-\mathrm{L}$ & 23,027 & 4.0 & 29,329 & 4.7 & 27.37 & $60.34 * *$ \\
\hline $1 \mathrm{~F}-\mathrm{R} \rightarrow 2 \mathrm{~F}-\mathrm{R}$ & 29,512 & 5.2 & 38,127 & 6.0 & 29.19 & $79.73 * *$ \\
\hline $1 \mathrm{~F}-\mathrm{L} \rightarrow 1 \mathrm{~F}-\mathrm{I}$ & 11,824 & 2.1 & 11,011 & 1.7 & 6.88 & $-19.22 * *$ \\
\hline $1 \mathrm{~F}-\mathrm{L} \rightarrow 2 \mathrm{~F}-\mathrm{I}$ & 11,311 & 2.0 & 14,055 & 2.2 & 24.26 & $43.91 * *$ \\
\hline $1 \mathrm{~F}-\mathrm{L} \rightarrow 2 \mathrm{~F}-\mathrm{L}$ & 9,893 & 1.7 & 12,714 & 2.0 & 28.52 & $81.25 * *$ \\
\hline $1 \mathrm{~F}-\mathrm{L} \rightarrow 2 \mathrm{~F}-\mathrm{R}$ & 15,522 & 2.7 & 19,224 & 3.0 & 23.85 & $42.16^{* *}$ \\
\hline $1 \mathrm{~F}-\mathrm{I} \rightarrow 2 \mathrm{~F}-\mathrm{I}$ & 9,544 & 1.7 & 11,252 & 1.8 & 17.90 & $32.94 * *$ \\
\hline $1 \mathrm{~F}-\mathrm{I} \rightarrow 2 \mathrm{~F}-\mathrm{L}$ & 9,312 & 1.6 & 10,957 & 1.7 & 17.67 & $-17.18^{* *}$ \\
\hline $1 \mathrm{~F}-\mathrm{I} \rightarrow 2 \mathrm{~F}-\mathrm{R}$ & 15,014 & 2.6 & 17,122 & 2.7 & 14.04 & n.s. \\
\hline $2 \mathrm{~F}-\mathrm{I} \rightarrow 2 \mathrm{~F}-\mathrm{L}$ & 13,045 & 2.3 & 12,722 & 2.0 & -2.48 & n.s. \\
\hline $2 \mathrm{~F}-\mathrm{I} \rightarrow 2 \mathrm{~F}-\mathrm{R}$ & 32,075 & 5.6 & 40,188 & 6.4 & 25.29 & $-17.41 * *$ \\
\hline $2 \mathrm{~F}-\mathrm{L} \rightarrow 2 \mathrm{~F}-\mathrm{R}$ & 33,399 & 5.9 & 32,442 & 5.1 & -2.87 & n.s. \\
\hline $1 \mathrm{~F}-\mathrm{L} \rightarrow 1 \mathrm{~F}-\mathrm{R}$ & 24,554 & 4.3 & 23,955 & 3.8 & -2.44 & 19.34 * \\
\hline $1 \mathrm{~F}-\mathrm{I} \rightarrow 1 \mathrm{~F}-\mathrm{R}$ & 26,684 & 4.7 & 29,468 & 4.7 & 10.43 & $-21.74^{* *}$ \\
\hline $2 \mathrm{~F}-\mathrm{I} \rightarrow 1 \mathrm{~F}-\mathrm{R}$ & 23,354 & 4.1 & 25,715 & 4.1 & 10.11 & $16.75^{* *}$ \\
\hline $2 \mathrm{~F}-\mathrm{L} \rightarrow 1 \mathrm{~F}-\mathrm{R}$ & 22,885 & 4.0 & 24,744 & 3.9 & 8.12 & n.s. \\
\hline $2 \mathrm{~F}-\mathrm{R} \rightarrow 1 \mathrm{~F}-\mathrm{R}$ & 29,473 & 5.2 & 34,712 & 5.5 & 17.78 & $14.24^{* *}$ \\
\hline $1 \mathrm{~F}-\mathrm{I} \rightarrow 1 \mathrm{~F}-\mathrm{L}$ & 21,541 & 3.8 & 21,011 & 3.3 & -2.46 & $19.85^{* *}$ \\
\hline $2 \mathrm{~F}-\mathrm{I} \rightarrow 1 \mathrm{~F}-\mathrm{L}$ & 11,284 & 2.0 & 11,047 & 1.8 & -2.10 & n.s. \\
\hline $2 \mathrm{~F}-\mathrm{L} \rightarrow 1 \mathrm{~F}-\mathrm{L}$ & 9,425 & 1.7 & 9,207 & 1.5 & -2.31 & n.s. \\
\hline $2 \mathrm{~F}-\mathrm{R} \rightarrow 1 \mathrm{~F}-\mathrm{L}$ & 14,525 & 2.5 & 13,971 & 2.2 & -3.81 & $-15.38^{* *}$ \\
\hline $2 \mathrm{~F}-\mathrm{I} \rightarrow 1 \mathrm{~F}-\mathrm{I}$ & 11,297 & 2.0 & 11,852 & 1.9 & 4.91 & $13.29 * *$ \\
\hline $2 \mathrm{~F}-\mathrm{L} \rightarrow 1 \mathrm{~F}-\mathrm{I}$ & 11,894 & 2.1 & 12,088 & 1.9 & 1.63 & n.s. \\
\hline $2 \mathrm{~F}-\mathrm{R} \rightarrow 1 \mathrm{~F}-\mathrm{I}$ & 14,938 & 2.6 & 15,084 & 2.4 & 0.98 & n.s. \\
\hline $2 \mathrm{~F}-\mathrm{L} \rightarrow 2 \mathrm{~F}-\mathrm{I}$ & 13,527 & 2.4 & 12,822 & 2.0 & -5.21 & $25.82 * *$ \\
\hline $2 \mathrm{~F}-\mathrm{R} \rightarrow 2 \mathrm{~F}-\mathrm{I}$ & 23,087 & 4.1 & 28,724 & 4.6 & 24.42 & $-13.79 * *$ \\
\hline $2 \mathrm{~F}-\mathrm{R} \rightarrow 2 \mathrm{~F}-\mathrm{L}$ & 26,112 & 4.6 & 24,927 & 4.0 & -4.54 & n.s. \\
\hline Total & 569,738 & 100.0 & 630,401 & 100.0 & 10.6 & 35.41 ** \\
\hline
\end{tabular}

Table 5. Statistical test for comparing pre and post sales by year.

\begin{tabular}{|c|c|c|c|c|c|}
\hline \multicolumn{6}{|c|}{ ANOVA Table } \\
\hline Source & DF & SS & MS & F-Value & $p$-Value \\
\hline Model & 2 & 1228323.23 & 6141615.61 & 5315.33 & $\underset{* *}{<0.0001}$ \\
\hline Error & 180 & 207981.72 & 1155.45 & & \\
\hline Corrected Total & 182 & 12491212.95 & & & \\
\hline \multicolumn{6}{|c|}{ LSM Adj. for Multiple Comparisons: Tukey-Kramer } \\
\hline & Year_Type1 & & Year_Type2 & & Year_Type3 \\
\hline Year_Type1 & - & & 0.1020 & & $<0.0001^{* *}$ \\
\hline Year_Type2 & 0.1020 & & - & & $<0.0001^{* *}$ \\
\hline Year_Type3 & $<0.0001^{* *}$ & & $<0.0001^{* *}$ & & - \\
\hline
\end{tabular}




\section{Conclusions}

We conducted three field experiments in three different timeframes. In each experiment, we rearranged one element of the VMD to compare customer movement patterns before and after the VMD change. In Study 1, we relocated display mannequins placed in the right-side zone near the entrance on the first floor (1F-right) to the inner side zone (1F-inner) and placed hangers with more clothing lines in that location. After the VMD rearrangement, the average daily sales of the first floor increased by about $10.6 \%$ from $\$ 5490$ to $\$ 6070$. In Study 2, we relocated the mannequin from the inner side zone (2F-inner) to the right-side zone (2F-right) on the second floor to secure a wide range of moving lines toward 2F-right, where men's suits with large unit sales were displayed. After the VMD rearrangement on the second floor, customers' average length of stay on the second floor increased from $9.6 \mathrm{~min}$ to $11 \mathrm{~min}$ or $14.6 \%$. In Study 3 , we cross-displayed men's and women's clothing lines. The effects of these rearrangements were measured by observing changes in sales. After cross-displaying (mixing) men's wear and women's wear, the average daily sales of women's products on the first floor increased by $10 \%$, thereby increasing the total average daily sales to $\$ 10,247$.

The main contributions of this research are summarized as follows. (1) While previous works on movement tracking data focus solely on developing algorithms to increase accuracy rate, we examine the sequences that customers follow when they browse the store. Furthermore, we link those movement data with sales data to find an optimal solution for store VMD design. Indeed, we strive to integrate the computing perspective with a marketing perspective. Although such an approach can benefit business practitioners, previous works on this topic are surprisingly limited. (2) Our research is particularly meaningful, because we conducted field experiments in a real-world store setting; moreover, it was a longitudinal study and was conducted over 4 months. (3) In this experiment, we compared customer movement patterns and transaction data before and after a store layout optimization decision to gain customer insights. One limitation of this study is that we do not provide a reliability index for testing how accurate our technology (indoor positioning system) is for identifying the customer's location. However, the data indicates that if a customer purchased a product, the last point of location is always identified as a POS (point of sales) according to indoor positioning system. We believe that it validates the accuracy of location positioning technology used in the study. Another limitation of this study is that we do not control for the potential loss of customers. If customers disappear within $180 \mathrm{~s}$ through the exit, it becomes difficult for us to track customers' flow of movements. In addition, the data matching between mobile data and POS data allows us to design the overall experiments and set research direction. This matching, however, may not be a perfect one-to-one match. We will develop a more sophisticated method for our future research. In practice, our findings can be utilized for not only store layout optimization but also personalized marketing. Using customer movement tracking data, retailers can deliver real-time personalized offers to their customers via mobile phones and can serve customers promptly. From a consumer's perspective, customer movement tracking data can help retailers discover the most efficient routes to products that consumers plan to purchase in a store and participate in deals or promotions that they otherwise would miss. Our work can function as a foundation for various practical applications of tracking data technologies.

Author Contributions: Conceptualization, H.H. and S.K.; Data curation, J.K.; Formal analysis, J.K.; Investigation, J.K., H.H. and S.J.K.; Methodology, H.H. and S.K.; Project administration, H.H.; Resources, H.H. and S.J.K.; Software, J.K.; Supervision, S.K.; Validation, S.J.K.; Visualization, J.K. and S.K.; Writing —original draft, J.K. and H.H.; Writing — review \& editing, S.K.

Funding: This research received no external funding.

Conflicts of Interest: The authors declare no conflict of interest.

\section{References}

1. Kerfoot, S.; Davies, B.; Ward, P. Visual merchandising and the creation of discernible retail brands. Int. J. Retail Distrib. Manag. 2003, 31, 143-152. [CrossRef] 
2. Mehta, N.; Chugan, P.K. The impact of visual merchandising on impulse buying behavior of consumer: A case from Central Mall of Ahmedabad India. Univers. J. Manag. 2013, 1, 76-82.

3. Park, H.H.; Jeon, J.O.; Sullivan, P. How does visual merchandising in fashion retail stores affect consumers' brand attitude and purchase intention? IJRDM 2015, 25, 87-104. [CrossRef]

4. Hwangbo, H.; Kim, Y.S.; Cha, K.J. Use of the Smart Store for Persuasive Marketing and Immersive Customer Experiences: A Case Study of Korean Apparel Enterprise. Mob. Inf. Syst. 2017, 2017, 1-17. [CrossRef]

5. Bleisch, S.; Duckham, M.; Galton, A.; Laube, P.; Lyon, J. Mining candidate causal relationships in movement patterns. IGISFR 2014, 28, 363-382. [CrossRef]

6. Hwangbo, H.; Kim, J.; Lee, Z.; Kim, S. Store layout optimization using indoor positioning system. Int. J. Distrib. Sensor Netw. 2017, 13, 1550147717692585. [CrossRef]

7. Kuntz, M.; Helbich, M. Geostatistical mapping of real estate prices: An empirical comparison of kriging and cokriging. Int. J. Geogr. Inf. Sci. 2014, 28, 1904-1921. [CrossRef]

8. Syaekhoni, M.A.; Alfian, G.; Kwon, Y.S. Customer purchasing behavior analysis as alternatives for supporting in-store green marketing decision-making. Sustainability 2017, 9, 2008. [CrossRef]

9. Waechter, S.; Sütterlin, B.; Borghoff, J.; Siegrist, M. Letters, signs, and colors: How the display of energy-efficiency information influences consumer assessments of products. Energ. Res. Soc. Sci. 2016, 15, 86-95. [CrossRef]

10. De Gregorio, F.; Sung, Y. Understanding attitudes toward and behaviors in response to product placement. J. Advert. 2010, 39, 83-96. [CrossRef]

11. Williams, K.; Petrosky, A.; Hernandez, E.; Page, R., Jr. Product placement effectiveness: revisited and renewed. JMMR 2011, 7,1.

12. Wu, J.; Won Ju, H.; Kim, J.; Damminga, C.; Kim, H.-Y.; KP Johnson, K. Fashion product display: An experiment with Mockshop investigating colour, visual texture, and style coordination. Int. J. Retail Distrib. Manag. 2013, 41, 765-789. [CrossRef]

13. Zhu, M.; Dong, J.; Gao, Y. The Research on Temporal-Spatial Distribution and Morphological Characteristics of Ancient Settlements in the Songhua River Basin. Sustainability 2019, 11, 932. [CrossRef]

14. Lux, M.; Anagnostopoulos, N.; Iakovidou, C. Spatial pyramids for boosting global features in content based image retrieval. In Proceedings of the 2016 14th International Workshop on Content-Based Multimedia Indexing (CBMI), Bucharest, Romania, 15-17 June 2016; 2016; pp. 1-4.

15. Owusu, G.; Wrigley-Asante, C.; Oteng-Ababio, M.; Owusu, A.Y. Crime prevention through environmental design (CPTED) and built-environmental manifestations in Accra and Kumasi, Ghana. Crime Prev. Community Saf. 2015, 17, 249-269. [CrossRef]

16. Law, D.; Wong, C.; Yip, J. How does visual merchandising affect consumer affective response? An intimate apparel experience. Eur. J. Mark. 2012, 46, 112-133. [CrossRef]

17. Kawaf, F.; Tagg, S. Online shopping environments in fashion shopping: An SOR based review. Market Rev. 2012, 12, 161-180. [CrossRef]

18. Jain, V.; Sharma, A.; Narwal, P. Impact of Visual Merchandising on Consumer Behavior towards Women's Apparel. IJRM 2012, 5, 106-117.

19. Swobodzinski, M.; Raubal, M. An indoor routing algorithm for the blind: development and comparison to a routing algorithm for the sighted. Int. J. Geogr. Inf. Sci. 2009, 23, 1315-1343. [CrossRef]

20. Kveladze, I.; Kraak, M.-J.; Van Elzakker, C.P.J.M. The space-time cube as part of a GeoVisual analytics environment to support the understanding of movement data. Int. J. Geogr. Inf. Sci. 2015, 29, 2001-2016. [CrossRef]

21. Sung, Y. RSSI-based distance estimation framework using a Kalman filter for sustainable indoor computing environments. Sustainability 2016, 8, 1136. [CrossRef]

22. Kim, D. Performance of UWB Wireless Telecommunication Positioning for Disaster Relief Communication Environment Securing. Sustainability 2018, 10, 3857. [CrossRef]

23. Tsai, H.-R.; Chen, T. Enhancing the sustainability of a location-aware service through optimization. Sustainability 2014, 6, 9441-9455. [CrossRef]

24. Yu, H.; Lee, H.; Jeon, H. What is 5G? Emerging 5G Mobile Services and Network Requirements. Sustainability 2017, 9, 1848. [CrossRef]

25. Curran, K.; Furey, E.; Lunney, T.; Santos, J.; Woods, D.; McCaughey, A. An evaluation of indoor location determination technologies. JLBS 2011, 5, 61-78. [CrossRef] 
26. Fallah, N.; A postolopoulos, I.; Bekris, K.; Folmer, E. Indoor human navigation systems: A survey. Interact Comput. 2013, 25, 21-33.

27. Liu, H.; Darabi, H.; Banerjee, P.; Liu, J. Survey of wireless indoor positioning techniques and systems. IEEE Trans. Syst. Man Cybern. Part C 2007, 37, 1067-1080. [CrossRef]

28. Chiou, Y.-S.; Wang, C.-L.; Yeh, S.-C. An adaptive location estimator using tracking algorithms for indoor WLANs. Wirel. Netw. 2010, 16, 1987-2012. [CrossRef]

29. Petrie, H.; Johnson, V.; Strothotte, T.; Raab, A.; Fritz, S.; Michel, R. MoBIC: Designing a travel aid for blind and elderly people. J. Navig. 1996, 49, 45-52. [CrossRef]

30. Gu, Y.; Lo, A.; Niemegeers, I. A survey of indoor positioning systems for wireless personal networks. IEEE Commun. Surv. Tutor. 2009, 11, 13-32.

31. He, S.; Chan, S.-H.G. Wi-Fi fingerprint-based indoor positioning: Recent advances and comparisons. IEEE Commun. Surv. Tutor. 2016, 18, 466-490. [CrossRef]

32. Xiao, Z.; Wen, H.; Markham, A.; Trigoni, N.; Blunsom, P.; Frolik, J. Non-line-of-sight identification and mitigation using received signal strength. IEEE Trans. Wirel. Commun. 2015, 14, 1689-1702. [CrossRef]

33. Li, Q.; Li, W.; Sun, W.; Li, J.; Liu, Z. Fingerprint and assistant nodes based Wi-Fi localization in complex indoor environment. IEEE Access 2016, 4, 2993-3004. [CrossRef]

34. Kim, Y.; Lee, J.; Jeong, J.; Chong, S. Multi-flow rate control in delayed Wi-Fi offloading systems. In Proceedings of the 2016 International Conference on Information Networking (ICOIN), Kota Kinabalu, Malaysia, 13-15 January 2016; pp. 274-279.

35. D. M. M. I. Center. Digital. Consumer and Korean Digital Lifestyle; Seoul, Korea, 2015; p. 12. Available online: http://www.dmcmedia.co.kr/notice/noticeView?dc_idx=22\&dn_idx=393 (accessed on 5 March 2018).

(C) 2019 by the authors. Licensee MDPI, Basel, Switzerland. This article is an open access article distributed under the terms and conditions of the Creative Commons Attribution (CC BY) license (http://creativecommons.org/licenses/by/4.0/). 